\title{
La responsabilidad social empresarial como estrategia de reproducción social
}

Trazos para su problematización

Brian Cañizares

Lic. en Trabajo Social

Maestrando en Trabajo Social

Centro de Estudios Interdisciplinarios en Problemáticas Internacionales y Locales (CEIPIL)

Universidad Nacional del Centro de la Provincia de Buenos Aires (UNCPBA)

E-mail: brianzeeb@hotmail.com 
Resumen

Nuestra presentación pretende aportar elementos de reflexión crítica respecto de las mediaciones activas y operantes en la dinámica de un tipo particular de respuesta a la "cuestión social" estructurado particularmente en función de programas de Responsabilidad Social Empresarial (en adelante RSE). A tal fin, se presentan como matriz de análisis ideas esenciales provenientes de las obras de Marx y de Lukács, intentando pensar cómo categorías como trabajo, trabajo abstracto, teleología, complejos sociales aportan a la comprensión del mencionado fenómeno a través de su problematización en cuanto estrategia que halla su base de sustento en el proceso de reestructuración del capital desde los años 70 , guardando relación con un determinado escenario de correlación de fuerzas que implica para las empresas, la necesidad de ganar legitimidad. Asimismo, se presentan y problematizan las funciones de la RSE, en tanto comprendida como estrategia de transmisión de ideología en el marco de la reproducción espiritual de las relaciones sociales que sustenta la división social del trabajo en la sociedad de clases. Se señalan asimismo aspectos problemáticos como disparadores de debate.
Abstract

Our presentation advances providing critic reflection elements regarding active and operating mediations on particular "social question" response, particularly structured over Corporate Social Responsibility (CSR in advance). For that purpose, essential ideas coming from Marx's and Lukács' work are presented, as trying to think how categories like work, abstract work, teleology, social complexes, contribute to the referred phenomenon comprehension through its problematization as an strategy based on capital's restructuring process from 1970 decade, as well as keeping related with forces correlations as it set for enterprises the need of gaining legitimacy. As well, CSR functions are presented as considered ideology transmitters in the context of spiritual social relations reproduction, sustaining social work division in classes' society. On this basis, problematical aspects are exposed as they try to function as debate triggers.

\section{Keywords}

social question - CSR

- work - ideology

\section{Palabras clave}

cuestión social - RSE -

Trabajo - Ideología 


\section{Presentación}

El fenómeno de la Responsabilidad Social Empresarial (en adelante, RSE) como fenómeno propio de la reestructuración del capital hacia mediados de la década del 70 nos coloca interrogantes respecto de su naturaleza, función y significado en cuanto estrategia de intervención sobre la "cuestión social".

El presente trabajo pretende aportar elementos de reflexión para pensar algunas de sus características y funciones considerando sus particularidades en el marco de las relaciones sociales de producción que le otorgan sentido.

Cuando nos enfrentamos a fenómenos contemporáneos como el analizado, surge el interés de comprender y aprehender el movimiento y significado que este adquiere en función de la correlación de fuerzas determinada por la coyuntura histórica. En este sentido, pretendemos abordar nuestro objeto partiendo del referencial legado por la obra marxiana y la tradición marxista, por cuanto encontramos en ella categorías que nos permiten aprehender el sentido y la dinámica de este tipo de estrategias. Así, consideramos que la recurrencia a la obra marxiana, cuando captada en su inmanencia, arroja elementos para entender no sólo el pasado sino la contemporaneidad.

El trabajo se estructura en tres apartados. En el primero se presentan categorías provenientes de la obra marxiana y lukácsiana que adquieren su utilidad, como matriz de análisis. En este sentido, encontramos que existen categorías a partir de las cuales es posible comprender los fenómenos actuales como fenómenos históricos, comprendiendo que esta historia es, a su vez, construida por los propios hombres como sujetos de praxis. En esta línea, intentamos desarrollar sintéticamente (y bajo la advertencia de que el abordaje cabal de algunas de estas categorías exigen un tratamiento riguroso y extensivo que no podemos realizar aquí, mas sobre el cual se referencian algunos autores) categorías tales como trabajo, en cuanto comprendida como praxis primaria humano-genérica. La implicancia teórica 
de esta elección radica en la consideración del trabajo como actividad singular del hombre, como actividad a partir de la cual es posible pensar la historia y el progreso humanos.

En este sentido, y a partir de la discusión sobre el trabajo, surge la necesidad de complejizar la comprensión de otra categoría que atraviesa la presentación, esto es, "teleología", momento a partir del cual es posible traer a la conciencia la ecuación de medios/fines y la elección entre alternativas en base a la consecución de una finalidad específica. Veremos cómo en el capitalismo, a través de la complejización del trabajo y el emplazamiento del "trabajo abstracto" surge otro tipo de teleología, de orden secundario, que adquiere su sentido en la esfera de la reproducción de las relaciones sociales. Teleologías estas destinadas a trasmitir un ordenamiento particular de las relaciones sociales.

Así, para pensar los alcances e implicancias de la estrategia de la RSE como estrategia de reproducción, a través de la explicitación de las debidas mediaciones, se llega a considerarla como un "complejo social". Como un portador práctico de relaciones de poder que adquiere su sentido en función de la colocación de teleologías de orden secundario sobre la conciencia de los hombres.

Ahora bien, en cuanto se pretende un abordaje de carácter histórico, resulta necesario pensar el surgimiento de la RSE como un surgimiento asociado a diferentes configuraciones históricas del capitalismo y del Estado burgués a lo largo de los siglos XIX y XX, a través de las cuales se torna posible identificar su sentido y su contextualización. Por lo cual el segundo apartado intenta esbozar una breve caracterización del contexto en el cual comienzan a erigirse las propuestas empresariales, intentando presentar el escenario de correlaciones de fuerza que rodea tales iniciativas. Veremos cómo entra en juego no sólo la intencionalidad de las empresas, sino cómo entran en juego demandas de diferentes actores. Es en este mismo punto en el cual se esbozan algunas características generales de la RSE.

Por último, se presenta una problematización de las funciones reproductivas de la RSE en tanto complejo social, y la implicancia que ello supone en cuanto elemento de transmisión de ideología. 
Asimismo, se señalan algunas aristas problemáticas de modo de abrir el juego al debate sobre aspectos que consideramos dilemas contradictorios de las propuestas empresariales, señalando la necesidad de seguir profundizando la discusión al respecto.

\section{Trabajo, trabajo abstracto y complejos sociales. Claves para pensar respuestas a la "cuestión social" y la RSE en particular}

De modo de establecer una matriz de análisis que nos permita aproximarnos a la discusión de las implicancias de la RSE en la marco de la sociedad capitalista, intentaremos aportar elementos para pensar las respuestas a la "cuestión social", considerando algunas categorías provenientes de la obra marxiana, tales como trabajo y trabajo abstracto, retomando la noción de complejos sociales acuñada por Lukács en su obra madura.

En principio, es preciso señalar que Marx señala al trabajo como la actividad fundamental que media en la relación entre hombre y naturaleza, más precisamente, la actividad mediante la cual el hombre transforma la naturaleza para la creación de bienes de uso conforme a sus necesidades. Al decir del propio Marx: "El proceso de trabajo (...) es la actividad racional encaminada a la producción de valores de uso, la asimilación de las materias naturales al servicio de las necesidades humanas, la condición general del intercambio de materias entre la naturaleza y el hombre, la condición natural eterna de la vida humana, y por tanto, independiente de las formas y modalidades de esta vida y común a todas las formas sociales por igual” (2003:119; cursivas en el original).

$\mathrm{Al}$ respecto, Lukács resalta que "la necesidad material, en cuanto motor del proceso de reproducción individual y social, es lo que realmente pone en movimiento el complejo de trabajo, y todas las mediaciones, de acuerdo con el ser, están presentes sólo para satisfacer esa necesidad" (2004:39). 
El trabajo como actividad primaria, única, universal del género humano, permite situar al hombre como actor capaz de establecer rupturas históricas, transformaciones de acuerdo al establecimiento de fines puestos, rompiendo con la pasividad ante lo dado. Así, el trabajo consistiría en la actividad humano-genérica que establece un límite respecto a la animalidad, para constituir el momento fundante de la humanidad. Marx señala al proceso de trabajo como la “... actividad racional encaminada a la producción de valores de uso, la asimilación de las materias naturales al servicio de las necesidades humanas, la condición general del intercambio de materias entre la naturaleza y el hombre, la condición natural eterna de la vida humana, y por tanto, independiente de las formas y modalidades de esta vida y común a todas las formas sociales por igual" (2003:119).

El aporte de Marx, de una singular claridad y especificidad teóri$\mathrm{ca}$, representa un enunciado de gran magnitud en cuanto constituye una ruptura en la comprensión del papel de hombre como protagonista de la historia (Lessa, 2008). Colocando sobre el hombre la posibilidad de objetivar actos de trabajo sobre su realidad (cualquiera esta sea), dimensiona en el ser la posibilidad de modificar (revolucionar) lo puramente dado a fin de responder a sus necesidades.

Esta concepción del trabajo, como actividad genérica, permite diferenciar al trabajo de concepciones que ligan al trabajo con la condición del salario o el trabajo remunerado propio de la sociedad de clases. Al respecto, vale traer la distinción que Marx incorpora en El Capital, respecto de las particularidades que este trabajo asume en la sociedad burguesa.

Con la sociedad de clases, y la consecuente apropiación de los medios de producción por parte de la burguesía, el trabajo como actividad primaria cede lugar a la forma de trabajo alienado, abstracto, cuyo fin último ya no responde a la satisfacción de necesidades del actor protagonista del acto de trabajo, sino a las necesidades del capitalista en base a la generación de plusvalía. En este marco, si bien el trabajador realiza un intercambio con la naturaleza, los resultados de este intercambio no se orientan a la satisfacción de necesidades propias, sino a las necesidades del circuito de circulación del capital. 
Al decir del propio Marx, en el capítulo XIV de El Capital: “de otra parte, el concepto de trabajo productivo ${ }^{1}$ se restringe. La producción capitalista no es ya producción de mercancías, sino que es, sustancialmente, producción de plusvalía. El obrero no produce para sí mismo, sino para el capital. Por eso, ahora, no basta con que produzca en términos generales, sino que ha de producir concretamente plusvalía. Dentro del capitalismo, sólo es productivo el obrero que produce plusvalía para el capitalista o que trabaja por hacer rentable el capital (2003:305; cursivas en el original).

El trabajo abstracto, como fenómeno del capitalismo, implica en sí la dislocación del sentido humano genérico del acto de trabajo, hacia el sentido de la producción de plusvalía bajo la primacía del fetichismo de la mercancía.

Debido a los límites de nuestra presentación, no podemos aquí desarrollar en profundidad las mediaciones y particularidades que operan en la caracterización del trabajo abstracto (tan bien desarrollados por el pensador alemán en su capítulo XIV de El Capital), es por ello que recuperaremos, a los fines de nuestra explicación, apenas los aspectos centrales del corpus teórico.

Ahora bien, pensar en los procesos de reproducción del capitalismo en el nivel de las relaciones sociales, remite a pensar en los mecanismos que operan en la reproducción del trabajo abstracto como momento fundante de la sociedad de clases. Para aproximarnos al tema, cabe rescatar la distinción que Lukács (2004) realiza entre las que denomina posiciones teleológicas primarias y posiciones teleológicas secundarias.

Fundamentalmente, Lukács asociará las posiciones teleológicas primarias a los actos primarios de trabajo, como dijimos, la transformación de la naturaleza para la creación de bienes de uso. Lukács describirá cómo el hombre efectiva el proceso de trabajo a través de momentos dialécticamente concatenados, diferenciando teleología:

1 Marx está comprendiendo en este pasaje, y en esta utilización particular de la categoría, al trabajo productivo como el trabajo en sentido humano genérico, como relación hombre-naturaleza, tal como desarrollado en el Capítulo V de El Capital. Ver Marx (2003), en especial Caps. V y XIV y la distinción claramente presentada entre trabajo productivo y trabajo productivo en su carácter abstracto. 
la representación ideal de aquella transformación a efectuar sobre el medio natural (momento que antecede a la acción); objetivación: esto es, el momento efectivo de la realización del acto teleológico sobre la naturaleza "la puesta en marcha de la corporeidad" (Marx, 2003); la exteriorización: refiere al momento en que el producto objetivado coloca sobre su creador nuevas necesidades, dando lugar a nuevos y singulares procesos de trabajo. Es justamente el componente consciente sobre el que Lukács hará particular hincapié para caracterizar los actos de trabajo, por cuanto identifica la esencia del trabajo en "la capacidad de rebasar la fijación del ser viviente en la relación biológica con su ambiente" (Lukács, 2004:39), señalando asimismo que "el momento esencialmente distintivo no está dado por la perfección de los productos, sino por el papel de la conciencia, que precisamente aquí cesa de ser un mero epifenómeno de la reproducción biológica: el producto es, dice Marx, un resultado que al comienzo del proceso estaba presente 'ya en la mente del obrero', es decir, de un modo ideal” (Lukács, 2004:40).

Por su parte, las posiciones teleológicas secundarias adquieren una lógica completamente distinta, así, mientras que las posiciones teleológicas primarias se orientan a la transformación y modificación de objetos naturales, las secundarias pretenden colocar su fin ya no sobre la naturaleza, sino sobre la "conciencia de un grupo humano" (Lukács, 2004:40). Este tipo de posición adquiere su particularidad en cuanto su función se ubica en favorecer tendencias en la elección de alternativas de otros individuos, recalca el pensador húngaro: "Este tipo de posición (...) no trabaja, en consecuencia, en un material en sí indiferente, sino en uno que es ya en sí favorable o desfavorable, y que se mueve tendencialmente hacia posiciones de fines" (Lukács, 2004:112).

Es así que la categoría de complejo social en cuanto conjunto de relaciones sociales con función de garantizar la reproducción de una determinada configuración de las relaciones sociales, adquiere su sentido. Por cuanto consiste en la colocación de fines puestos, sobre la conciencia de otros hombres. Señala Lessa (1999) que, en el contexto 
de la sociedad de clases, los complejos sociales se convierten en "portadores prácticos" del poder de unos sobre otros.

Los complejos sociales se orientan particularmente en la división social del trabajo a la manutención de las relaciones sociales que sustentan al capital como principio rector de la sociabilidad. Como bien señala Lukács (2004), la relación de los complejos sociales con el trabajo, se da en una relación indirecta, por cuanto no interviene directamente sobre mecanismos de producción, sino que se mueven en el plano de la reproducción social.

A este respecto, Lukács (1981) refiere que es justamente función de estos complejos sociales la reproducción de las relaciones sociales en cuanto derivaciones de una totalidad mayor que les otorga sentido y direccionalidad. Cuando el autor aborda los "problemas generales de la reproducción" ser social, hasta en su estado más primitivo, representa un complejo, donde hay interacciones permanentes sea entre los complejos parciales, sea entre el complejo total y sus partes. De aquí se desarrolla el proceso reproductivo del complejo social en cuestión, en el cual también los complejos parciales se reproducen como hechos autónomos -aunque sólo relativamente-, mas en cada uno de tales procesos es la reproducción de la totalidad que, en este múltiple sistema de interacciones, constituye el momento predominante" (Lukács, 1981:3; t.p.).

Sin pretender extendernos en la discusión de la reproducción, por cuanto exigiría un tratamiento específico y la discusión de textos fundamentales ${ }^{3}$ de los referidos autores, intentamos rescatar la idea de la funcionalidad de los complejos sociales la reproducción de la división social y técnica del trabajo.

Considerando la sociedad de clases, podemos identificar una serie de complejos tradicionales como el derecho, la educación y las políticas sociales ${ }^{4}$, mientras que persisten, es necesario aclarar, otros

2 Ver Lukács (1981).

3 Sin dudas, son fundamentales en este debate Marx (2003 y 2010) y Lukács (1981 y 2004$).$

4 Algunos autores problematizan mediaciones que permiten considerar a las políticas sociales e incluso al Trabajo Social como complejo social. Al respecto, resultan sumamente pertinentes Costa (2000) y Gianna y Mallardi (2011). 
de tipo universal (claro que no independientes de sus determinantes materiales), tales como el lenguaje.

En la contemporaneidad, existen asimismo una serie de complejos sociales que, en tanto dinámicos e históricos, se presentan aggiornados y actualizados conforme a las necesidades del desarrollo de las fuerzas productivas. Es decir, como necesidades puestas (teleológicamente) por una clase social en un momento específico de la historia.

Es así, como algunas formas de respuesta a la "cuestión social" se constituyen en complejos sociales en cuanto en su pretendida apariencia de respuesta a determinadas dimensiones de problemas sociales, intentan reproducir los principios hegemónicos de la conservación de la subalternización de la pobreza y el refuerzo de mecanismos de corte clientelista de la asistencia. Intentan imprimir una teleología basada en la reproducción espiritual (Iamamoto, 2004) de las relaciones sociales.

Planteado el marco teórico de nuestro análisis, consideramos necesario profundizar dos aspectos centrales para avanzar en la caracterización y problematización de la RSE. Por una parte, es preciso considerar las particularidades del surgimiento histórico de la RSE y, con ello, realizar una aproximación al contexto político-económico en el cual se inscribe; de otra, problematizar las funciones reproductivas y la implicancia de la teleología de orden secundario en la comprensión de la RSE en el marco capitalista actual.

\section{Contexto histórico de surgimiento de la RSE}

Las diversas manifestaciones de la "cuestión social" en cuanto derivadas de tensión capital-trabajo en la sociedad burguesa, han requerido históricamente formas de intervención que asumen sus particularidades y direccionalidades en función de las distintas coyunturas históricas.

Es posible identificar momentos diferenciados y, por ende, diferentes estrategias de aproximación a los problemas sociales como manifestaciones fragmentadas de la "cuestión social" (Netto, 2002). 
Ubicando la identificación del reconocimiento de la "cuestión social" y la incorporación en tanto agenda por parte de las clases dominantes de los problemas denunciados por la clase trabajadora, en los procesos revolucionarios del siglo XIX, es posible identificar un recorrido histórico que, sujeto a las condiciones derivadas de los distintos momentos del desarrollo de las fuerzas productivas, llevarán a la burguesía, principalmente mediante aquel que se constituye en el aparato legítimo del ejercicio del poder, el Estado, a intervenir sobre los problemas denunciados por la clase trabajadora.

Sobre dicho recorrido histórico, e intentando circunscribir nuestro análisis a aspectos específicos de la emergencia de respuestas novedosas a la "cuestión social", no podemos más que mencionar someramente algunas de sus particularidades, analizando las características que el Estado asume en las distintas coyunturas, pero centrándonos principalmente en las condiciones que sirven de base al surgimiento de la RSE como fenómeno contemporáneo.

Trayendo a colación los aportes de Parola (2009), es posible identificar distintos roles del Estado en función de las configuraciones históricas del capitalismo. Así, una primera fase puede ser categorizada como de Estado mínimo durante el período que comprende al denominado capitalismo mercantil que se extiende de 1800 a $1930^{5}$, el cual supone fundamentalmente una intervención centrada en la coerción y la represión. Las principales acciones del Estado estarán vinculadas a la intervención en materia económica, exhibiendo su fase más funcional al naciente capitalismo bajo la premisa de sostener, ante todo, la libre circulación de capitales y garantizar la propiedad privada y el mercado libre.

Un segundo período, comprendido entre los años 1930-1970, se refiere al llamado capitalismo monopolista o fase de capitalismo imperialista, caracterizada por una división social y técnica del trabajo de carácter complejo, basado en el binomio taylorismo-fordismo y la producción de stock. Durante esta etapa el Estado persigue una doble finalidad: por un lado afrontar, a través de políticas sociales e inver-

5 Las fechas se presentan en términos aproximativos y a término general. 
sión en infraestructura, los costos necesarios a la reproducción de la fuerza de trabajo (Netto, 2002), sin la cual sería imposible cualquier reproducción del sistema (Lessa, 2011); por otro, para garantizar un mínimo de cohesión y "paz social”, intentando aplacar el "descontento social" y disminuir el riesgo de la posibilidad de un accionar revolucionario por parte de la clase trabajadora. El Estado exhibe así su fase social, en lo que comúnmente se denomina Estado del Bienestar.

Por último, una tercera etapa que podríamos identificar como capitalismo tardio, caracterizado por la financierización de los capitales; una re-configuración de la división social y técnica del trabajo a escala global con base en el just-in-time y la incorporación de una alta tecnificación de la producción según el patrón toyotista ${ }^{6}$ (Antunes, 2005), exhibe, una vez más, una actuación mínima por parte del Estado en materia social. Apoyando los preceptos de una economía global basada en la libre competencia y en la responsabilidad individual de los sujetos para con su propia "suerte", el Estado operará un fuerte recorte en materia de política social y gasto público. Es así que gana terreno la privatización de los servicios básicos de infraestructura (transporte, servicios públicos tales como el acceso a la electricidad y el agua potable) y la revalorización del mercado como el espacio de satisfacción de las demandas.

Se establecen entonces políticas sociales con un fuerte carácter residual favoreciendo el surgimiento de respuestas alternativas a las manifestaciones de la "cuestión social". Se asiste al fortalecimiento de espacios comprendidos en la genérica (y no poco problemática ${ }^{7}$ ) categoría del "tercer sector". Entendiendo por el mismo una numerosa serie de actores sociales e instituciones de índole privado ${ }^{8}$ que, mediante diferentes configuraciones intentarán complementar la acción del Estado y constituir en ocasiones la opción privilegiada como

6 Lessa realiza un abordaje problematizador de la ilusión de ruptura entre el binomio taylorismofordismo y toyotismo, encontrando, a contramano de muchos autores del mainstream académico, elementos de una marcada continuidad entre ambos modelos de producción en función de su carácter burgués. Al respecto, ver Lessa (2011), en especial el cap. IX.

7 Ver Montaño (2005).

8 Consideramos "privado" en un doble sentido: en cuanto a privacidad civil, estos es, de cada ciudadano por fuera de la injerencia del Estado y, asimismo, como referencia a la propiedad privada. 
forma de respuesta a las necesidades derivadas de las problemáticas sociales.

Este "tercer sector" a menudo desregulado, a menudo al amparo de un difuminado marco regulatorio, da lugar a la aparición o el refuerzo del accionar de actores que tanto se debaten entre espacios de resistencia al neoliberalismo, como podría considerarse la configuración de diversos movimientos sociales ${ }^{9}$ surgidos en este contexto, así como la aparición en escena de actores privados, empresariales, asumiendo "nuevas" formas de intervención sobre la "cuestión social" como la RSE.

Es así que, ante un Estado en retirada del enfrentamiento de la "cuestión social", el escenario se plantea como un espacio propicio a la emergencia y fortalecimiento de este tipo de intervenciones, más no únicamente respondiendo esta variable, sino también en cuanto estrategia llamada a posicionar al mercado como un actor capaz de proveer bienestar.

Es importante reparar en el rol del Estado, pues esto permite pensar en una articulación funcional de la configuración del Estado mínimo con la iniciativa empresarial de "enfrentar" la "cuestión social”. Aquí, el accionar de las empresas a través de la RSE encuentra su espacio de oportunidad, tendiendo a suplir aquellos espacios que (por omisión en contraste con la acción), quedarían desprovistos de atención, quedando relegados a la suerte (o iniciativa individual).

Vale la pena aclarar que el surgimiento de la RSE, como ya analizáramos en una anterior aproximación (Cañizares, 2010), no se explica solamente a través de la acción o la omisión del Estado respecto del enfrentamiento a la "cuestión social", sino también por factores específicos derivados de fenómenos producto de la lucha de clases. Así, ubicando el origen de la RSE en las décadas del 60 y 70, es posible observar en el escenario histórico, la presencia de un actor movilizado en torno a intereses comunes, la clase trabajadora organizada.

9 Al respecto, es preciso decir que deben considerarse las mediaciones necesarias para caracterizar los movimientos sociales como espacios asociados a momentos de resistencia. Al respecto, Marro (2006) realiza una brillante aproximación aportando elementos de reflexión respecto a las particularidades de los movimientos sociales en el marco de los antagonismos de clase. 
A través de distintas configuraciones históricas (el fortalecimiento de la representación sindical, la protesta social, el fortalecimiento de la identificación de clase en las demandas colectivas, etc.), la clase obrera pretende impugnar el orden del capital, al mercado como principio rector de la sociabilidad.

El fortalecimiento y surgimiento de las estrategias de RSE no es ajeno a ello. Asociadas a una intencionalidad de exhibir al capitalismo en clave humanitaria, las empresas (organizadas en torno a grupos económicos) comienzan a vislumbrar la necesidad de orientarse hacia un perfil "solidario" y repensar su orientación ética. En este sentido, algunos hitos históricos tales como la creación de la OCDE (1960) y el Club de Roma (1968), y la Declaración tripartita de principios sobre las empresas multinacionales y la política social de la OIT (1977), son indicadores de este proceso ${ }^{10}$.

Las empresas se proponen entonces como estrategia, reproducir aquello que De Souza Martins (1982) califica como "modo capitalista de pensar", mas no lo hacen de forma inmediata, sino, valga la redundancia, mediatizando esta reproducción a través de programas destinados a atender algunas manifestaciones de la "cuestión social". Intentando realzar la dimensión discursiva y de imagen, en contraste con la transferencia efectiva de recursos, y trasmitiendo teleológicamente una forma de comprender la solidaridad.

El fortalecimiento de este tipo de iniciativas, guarda relación histórica con el proceso de afianzamiento del neoliberalismo hacia finales de la década del 70, y ya en los 80 y 90, comienzan a visualizarse con mayor claridad en la aparición de fundaciones de empresas multinacionales (Coca-Cola y Mc Donalds, son algunos de los ejemplos más emblemáticos). Experiencias similares se replican en el plano nacional en Argentina, tanto en casos de empresas extranjeras como algunas nacionales o de capitales mixtos.

En líneas generales, los programas de RSE en la Argentina tienden a afectar a temáticas mayormente relacionadas con niñez, en cuanto apoyo a la educación, programas de apoyo escolar, otorgamiento de

10 Este proceso es abordado con mayor profundidad en Cañizares (2010). 
becas y pasantías; así como, en algunos casos, la acción se orienta a la contención de población adolescente. Siendo posible identificar en los discursos empresariales la intencionalidad de apostar al "desarrollo sustentable", al "empoderamiento de las comunidades", los emprendimientos de las empresas, no se plantean la solución cabal de problemáticas, sino más bien, el otorgamiento de ayudas solidarias desinteresadas, profesando un interés por las comunidades en las que las empresas se emplazan.

Problematizando este y otros aspectos es que nos proponemos a continuación plantear algunas mediaciones entre el cuerpo categorial planteado en el primer punto, a modo de aproximarnos a una revisión crítica de la RSE, intentando establecer cómo y por qué es posible entender a las iniciativas empresariales como teleologías secundarias.

\section{RSE como complejo social. Aproximaciones para un análisis problematizador}

Ahora bien, mencionamos antes la entrada en escena del "tercer sector" en el enfrentamiento a la "cuestión social" como el espacio en donde cobran importancia actores de tipo privado.

La RSE surge y cobra fuerza como resultado de un doble proceso: por un lado, relacionado a la reestructuración productiva del capital desde mediados de la década del 70, en función del establecimiento de nuevos patrones de productividad y organización del trabajo, atendiendo a la necesidad de la burguesía de tornar aceptable la intensificación de la explotación de la fuerza de trabajo, el subempleo y la re-apropiación del tiempo libre; por otro, como estrategia que complementa la retirada ${ }^{11}$ del Estado considerando las políticas sociales y la apertura del juego hacia fuentes alternativas de satisfacción de demandas de las clases subalternas.

11 Al respecto, valga hacer la aclaración que esta retirada del Estado, implica apenas un alejamiento del Estado en materia social, no así en la desregulación de la economía. 
Al respecto de lo segundo, Dias Da Cunha señala que la RSE "surge en el contexto de la reestructuración del capital relacionada a los intereses dominantes en la reposición de nuevos niveles de rentabilidad económica, de reapropiación, por el capital, del control de la fuerza de trabajo y en la búsqueda del refuerzo al envolvimiento cooptado del trabajador a los actuales protocolos de la producción flexible” (2007:33; t.p.).

Se asiste a los llamados procesos de refilantropización de lo social, en un proceso en el cual, siguiendo a Otormin (2000), la intervención en lo social -es decir sobre manifestaciones de la "cuestión social"es mercantilizada y trasladada al espacio de la solidaridad y el altruismo de diversos actores no-estatales. En este sentido, es claramente visible cómo las posiciones teleológicas secundarias expresadas en los programas de RSE, conllevan esta intención de representar "valores" empresariales como la solidaridad, la cooperación, el compromiso social, de forma de reforzar las relaciones sociales que tornan aceptable las condiciones deshumanas del capitalismo.

La importancia y la funcionalidad de los programas de RSE se observa no tanto en el plano de los problemas que pretende "subsanar", sino en el impacto que las intervenciones tienen a nivel de la subjetividad de los destinatarios de los programas o beneficios.

Es a partir de aquí que se establecen algunas mediaciones necesarias para comprender en qué medida puede la RSE ser entendida como un complejo social, esto es, portadora de una teleología de orden secundario.

El fundamento de esta afirmación radica en varios aspectos. Uno de ellos consiste en que, en contraste con la dimensión discursiva supervalorada de este tipo de programas, el grado de resolución o impacto o efectividad en el enfrentamiento de la "cuestión social" resulta mínimo, bien por el desembolso ínfimo de fondos en comparación con las ganancias de las actividades empresariales, bien por los objetivos mismos de los programas, los cuales siquiera se proponen la "solución" o atención de problemas sociales comprendidos en sus implicancias históricas. 
Por otra parte, la dimensión discursiva se asocia a la transmisión de una forma de pensar y actuar, de una visión de mundo, en definitiva una particular organización de las relaciones sociales. Su contenido teleológico apunta directamente a la transmisión de una ideología basada en la hegemonía del capital.

Como ya mencionamos, el sentido fundamental de la RSE, en cuanto complejo social, consiste en la transmisión de un modelo de sociedad, mediante la instrumentación de un modelo de resolución de los problemas sociales que implica una concepción de los mismos en tanto "situaciones" que pueden ser resueltas en la esfera de la individualidad, y para lo cual los individuos tendrían la posibilidad de "aprovechar" la ayuda solidaria y desinteresada de los actores empresariales. Conforme a su lógica reproductiva, este complejo social actúa aquí "orientando tendencialmente" (Lukács, 2004) las opciones de los usuarios de los programas en la resolución de sus necesidades, intentando colocar como premisa el cariz humanitario, el "lado amable”, del sistema basado en la explotación del hombre por el hombre.

Esta imagen de la empresa, como actor neutro, solidario, agente del bien común, supone en el discurso empresarial la identificación a modelos y representaciones específicos que responden a proyectos de sociedad igualmente específicos. Como bien señalan Mancinas Espinoza y Zúñiga Coronado, "el proyecto de la RSE trae consigo una lógica de funcionamiento subyacente a la caridad y la filantropía, y consecuentemente una forma de entender y atender lo social" (2012:4). Así intentando favorecer la reproducción espiritual de las relaciones sociales, la RSE intenta legitimar a la empresa en cuanto actor solidario, ocultando los mecanismos de explotación de la fuerza de trabajo y la apropiación del tiempo libre de los trabajadores.

La empresa se presenta entonces desligada de la generación de desigualdades, por fuera de la participación en los mecanismos de explotación de la fuerza de trabajo, por fuera de la obtención de plusvalía y sin siquiera pensarse como parte usufructuaria del trabajo abstracto que los trabajadores reproducen en la dinámica empresarial.

Insistimos con el contenido profundamente ideológico de la RSE, por cuanto reporta un importante contenido de convencimiento ha- 
cia los sujetos, sea de la bondad o solidaridad de la empresa, como de valores como el mérito y el individualismo. Adquieren relevancia los aportes de Macedo Da Costa, cuando afirma que "en las posiciones teleológicas secundarias las acciones entre los hombres es mediada, más o menos intensamente y aunque en términos muy generales y abstractos, por actos de convencimiento de individuos para que otros actúen conforme lo deseado" (2013:13). Dicha transmisión de "valores" reporta con claridad, en el caso de la RSE, una funcionalidad directa para con el capital.

Comprendiendo que la finalidad de los complejos sociales, termina siendo actuar sobre la conciencia de los hombres, comprendiendo a la conciencia como "aquella que regula las acciones prácticas del individuo en la vida cotidiana” (Macedo Da Costa, 2013:12), la RSE se asocia a un intento por regular el accionar de los usuarios de los programas. Tendiendo a colocar teleológicamente comportamientos y concepciones que justifiquen la propiedad privada y la explotación del hombre por el hombre. Intentando incidir "sobre los actos de conciencia de los individuos y grupos, movilizando fuerzas psíquicas en base a valores, hábitos, actitudes, normas sociales, procesos educativos, políticos y otros más" (Macedo Da Costa, 2013:12). Dichos aspectos, siempre considerados desde la óptica de la reproducción del Capital.

Quizás sea oportuno traer a colación los aportes que Thwaites Rey coloca, retomando a Gramsci, respecto de la recurrencia a estrategias de imposición de hegemonía a través de mecanismos mucho más sutiles que la simple coacción. Menciona la autora, considerando al pensador italiano, que "lo que con mayor énfasis quiere destacar Gramsci es que la clase dominante ejerce su poder no sólo por medio de la coacción, sino además porque logra imponer su visión del mundo, una filosofía, una moral, costumbres, un 'sentido común' que favorecen el reconocimiento de su dominación por las clases dominadas" (Thwaites Rey, 1994:13).

Con ello, hacemos referencia a que la RSE debe ser comprendida en el marco más amplio determinado por la intención por parte del capital, de establecer puntos de legitimación respecto de su accionar 
y su imaginario a nivel de la conciencia. En este sentido hayamos que considerar a la RSE como un complejo social basado en la reproducción de la ideología capitalista, y por ello en la reproducción de relaciones sociales de producción, termina siendo una opción que permite la problematización de sus aspectos sencillamente fenoménicos.

\section{Consideraciones finales e interrogantes abiertas}

Hemos intentado a lo largo de nuestra presentación, realizar una aproximación crítica a las estrategias de RSE como formas de intervención sobre la "cuestión social".

Para ello, nos parece importante recuperar como clave de análisis categorías fundamentales de la obra marxiana y lukácsiana como lo son trabajo, trabajo abstracto, teleología, complejo social. En este sentido, creemos que la resignificación de la ortodoxia como principio de abordaje teórico-metodológico reviste una importancia central en cuanto pensamos la ortodoxia en términos gramscianos, en esta intención de referirnos a las fuentes auténticas como fuentes de comprensión de lo real, como posibilidad de "construir no sólo una concepción de mundo total e integral (...) sino para vivificar una organización práctica integral de la sociedad, es decir, para convertirse en una civilización total, integral" (Gramsci, 2012:63; cursivas nuestras) ${ }^{12}$.

Este abordaje nos permitió establecer que el trabajo, como actividad humano genérica, representa una característica de orden ontológico en el ser social, observando cómo la base del trabajo en su sentido más básico (esto es, la transformación consciente de la naturaleza en manos del hombre), ve dislocado su sentido de libertad ${ }^{13}$ ante la configuración del trabajo abstracto en la sociedad de clases.

12 Gramsci hace referencia en este pasaje a la importancia de la ortodoxia para pensar lo que él denomina filosofía de la praxis. Nos parece sin embargo, completamente pertinente la utilización de esta cita, mutatis mutandis, para ilustrar nuestra posición respecto de la relevancia de la ortodoxia como principio metodológico.

13 Lukács, en la Ontología, reconoce haber sin embargo una relación siempre contradictoria y necesariamente problemática entre libertad y necesidad. Ver Lukács (2004), en especial caps. II y III. 
Así, identificando las determinaciones esenciales y la funcionalidad de las teleologías secundarias, se avanzó en desarrollar la categoría de complejo social introducida por Lukács, y, a través de su explicitación, recalcamos su utilidad para aproximarnos al fenómeno de la RSE en tanto posición teleológica secundaria y mecanismo de reproducción espiritual de las relaciones sociales en la sociedad capitalista. Reportando asimismo un claro componente de transmisión ideológica, tendiendo a colocar teleologías de orden secundario que conllevan consigo comportamientos y concepciones afines a la reproducción del capital. Se analizaron, por su parte, las tensiones y dilemas que la intervención social de las empresas supone en el mismo seno de su reproducción.

Para cerrar, quisiéramos sostener que, basados en el desarrollo precedente, podríamos calificar a la RSE como una estrategia esencialmente reproductiva de las relaciones sociales; que no apunta a la resolución de problemas sociales; que no pretende influir en el nivel subjetivo para otra cosa que no sea el refuerzo de la hegemonía del capital, y se vale para ello de estrategias que tienden a disociar causas de consecuencias, que tienden a ocultar el peso que asume la actividad empresarial sobre la determinación de los problemas sociales, la lucha de clases y las desigualdades, respecto a su lugar en la estructura productiva; que asimismo pretende velar o dislocar las diferencias en las asimetrías de poder entre los actores empresariales y los beneficiarios de los programas, ensayando discursos de solidaridad y cooperación en una ficción discursiva disonante.

A modo de aportar interrogantes e introducir aristas de debate respecto de la temática y sus implicancias, mencionamos, por último, algunos dilemas intrínsecos de la RSE en su enfrentamiento a la "cuestión social". A este respecto, nos parece oportuno presentar las siguientes reflexiones:

- El primer dilema refiere a la imposibilidad de afectar a las manifestaciones de la "cuestión social" con un sentido cabal de resolución de problemas. En este sentido, entran en juego dos variables: por una parte, en cuanto complejo social, el contenido teleológico de las acciones llevadas adelante implica un desarrollo de las interven- 
ciones basado en la reproducción espiritual de las relaciones sociales, antes que un accionar material concreto; por otra, intervenir sobre las causas de los problemas, llevaría a la RSE a plantearse ante su propio límite, en el sentido de la imposibilidad de pensar un posicionamiento crítico-resolutivo más allá de los patrones de la explotación de la fuerza de trabajo y la obtención de plusvalía.

- El segundo dilema consiste en la intención por parte de la RSE de presentarse como un actor escindido de la causa de los problemas sociales; de situar el accionar de las empresas por fuera de la generación de las desigualdades. En este sentido, el obstáculo a este complejo social, se identifica en tanto pretende mostrar la "cara humanitaria" del capitalismo, en el marco de a aquello que Guerra (2000) califica de "estrategia de racionalización de la crisis capitalista". En el imaginario de la RSE, la empresa es vista como un vecino más en las comunidades. Sin que medie ningún reparo en las asimetrías de poder derivadas de su posición en la estructura productiva.

- Como corolario de los dilemas anteriores, el tercer gran "callejón sin salida" de la RSE se ubica llanamente en el terreno de la amenaza de su contradicción. Esto es en cuanto, en términos generales, y por cuanto las empresas representan en un sentido de lo más explícito, la dinámica del capitalismo, la mismas no pueden pensarse por fuera de la desigualdad estructural de clases, de la explotación de hombre por el hombre, de la disociación del sentido humano genérico del trabajo hacia el trabajo abstracto, con los necesarios efectos deshumanizantes para la mayoría de la población.

Aún bajo estas premisas, las empresas, configuraciones burguesas de explotación por excelencia, pretenden afectar (siempre priorizando, claro está, el terreno subjetivo) mediante sus estrategias de RSE, las manifestaciones de la "cuestión social". Cabe preguntarnos: ¿Cómo realizan esto sin negarse a sí mismas? ¿Pueden las empresas garantizar algún grado de resolución de los problemas sociales? ¿Son pensadas siquiera las manifestaciones de la "cuestión social" en tanto procesos sociales históricos? ¿Cuál es, en última instancia, la posibilidad efectiva de que un complejo social de esta magnitud y con estas características, en cuanto posición teleológica secundaria, pueda in- 
cidir en la transformación objetiva de las desigualdades derivadas de la división de clases?

El fenómeno de la RSE supone a la investigación de corte crítico, el desafío de develar sus determinaciones, sus mediaciones, sus significados tomando como marco la lucha de clases. Esperamos, en este sentido, haber aportado elementos de reflexión que permitan avanzar en esa dirección.

\section{Referencias bibliográficas}

ANTUNES, R. Los Sentidos del Trabajo - Ensayo sobre la afirmación y la negación del trabajo. Buenos Aires. Ediciones Herramienta/ Taller de Estudios Laborales, 2005.

CAÑIZARES, B. Z. Responsabilidad Social Empresarial: Análisis de sus implicancias y estrategias de intervención sobre la "cuestión social". Tesis de Licenciatura en Trabajo Social, Facultad de Ciencias Humanas - Universidad Nacional del Centro de la Provincia de Buenos Aires. Tandil, mímeo, 2010.

COSTA, G. "Aproximação do Serviço Social como Complexo Ideológico”, em: Revista Temporalis $\mathrm{N}^{\circ}$ 1. Brasília, 2000.

DIAS DA CUNHA, N. M. O trabalho voluntário e a responsabilidade social empresarial: a expropriação do tempo livre como uma estratégia de envolvimento cooptado do trabalhador. Programa de Pós - Graduação em Políticas Públicas (PPGPP), Centro de Ciências Sociais (CCSO), Universidade Federal do Maranhão (UFMA), São Luis, 2007.

GIANNA, S. Y MALLARDI, M. "El trabajo social como complejo social. Aproximación a los fundamentos de los procesos de intervención profesional”, en: Revista Debate \& Sociedade V. 1 / Nº 1, Uberlândia, 2011.

GUERRA, Y. "La crisis contemporánea y los impactos en la instrumentalidad del trabajo social”, en: Boletín Electrónico SURÁ, $N^{\circ} 45$, Costa Rica, 2000. Traducción por Carina Moljo. [En línea: 22 de noviembre de 2012] Disponible en: http://www.ts.ucr.ac.cr/ suradoc.htm

GRAMSCI, A. "La política y el Estado moderno”, en: Revista Ñ. Biblioteca Pensamiento Crítico. Buenos Aires, Editorial Sol 90, 2012.

HOBSBAWM, E. La era de la revolución. 1879-1848. Buenos Aires, Crítica, 2007a.

HOBSBAWM, E. La era del capital. 1848-1875. Buenos Aires, Crítica, 2007b. 
IAMAMOTO, M. V. "As dimensões ético-políticas e teórico-metodológicas no Serviço Social contemporâneo. Trajetória e desafíos”, en: Molina, M. L. (Org.) La cuestión social y la formación profesional en trabajo social en el contexto de las nuevas relaciones de poder y la diversidad en Latinoamérica. Buenos Aires, Editorial Espacio, 2004.

LESSA, S. "El processo de produção/reprodução social; trabalho e Sociabilidade", em: Capacitação em serviço social e política social. San Pablo, CEAD, 1999.

LESSA, S. "Trabalho e luta de classes na sociedade de conhecimento", em: JIMENEZ, S; DE OLIVEIRA, J. y SANTOS, D. (orgs.) Marxismo, Educação e Luta de Classes. Fortaleza, UECE/IMO/SINTSEF, 2008.

LESSA, S. Trabalho e proletariado no capitalismo contemporâneo. San Pablo, Cortez Editora, 2011.

LUKÁCS, G. [1981] Ontología del ser social: La reproducción. [En línea: diciembre de 2012] Disponible en: http://www.sergiolessa.com

LUKÁCS, G. Ontología del ser social: El trabajo. Buenos Aires, Herramienta, 2004.

MACEDO DA COSTA, G. "Aproximación al Servicio Social como Complejo Ideológico", en: Cátedra libre: marxismo y trabajo social. Serie Debates Actuales en Trabajo Social, mayo de 2013. [En línea: julio de 2013] Disponible en: http://www. catedralibrets.wix.com/publicaciones

MANCINAS ESPINOZA, S. y ZÚÑIGA CORONADO, M. "Post política y refilantropización de lo social. Implicaciones en la formación de trabajadores sociales en México", ponencia presentada en: XX Seminario Latinoamericano de Escuelas de Trabajo Social, Córdoba, Argentina, 2012.

MARRO, K. "Algunos criterios metodológicos de interpretación histórico-crítica del movimiento social en sus múltiples expresiones", en: Observatorio Social de América Latina-CLACSO, Buenos Aires, 2006.

MARX, K. El Capital .Tomo I. Soporte PDF, Marxists Internet Archive, 2003.

MARX, K. y ENGELS, F. La Ideología Alemana. Buenos Aires, Nuestra América, 2010.

MONTAÑO, C. Tercer Sector y Cuestión Social. Crítica al patrón emergente de intervención social, San Pablo, Editorial Cortez, 2005.

NETTO, J. P. Capitalismo monopolista y servicio social. San Pablo, Editorial Cortez, 2002 .

OTORMIN, F. “Transformaciones en el trabajo y en el servicio social”, en: Boletín Electrónico SURÁ, N 48, Costa Rica, 2000. [En línea: 22 de noviembre de 2012] Disponible en: http://www.ts.ucr.ac.cr/suradoc.htm

PAROLA, R. Producción de conocimiento en trabajo social. Una discusión acerca de un saber crítico sobre la realidad social. Buenos Aires, Espacio Editorial, 2009. 
THWAITES REY, M. "La noción gramsciana de hegemonía en el convulsionado fin de siglo. Acerca de las bases materiales del consenso", en: FERREIRA, L; LOGIUDICE, E. y THWAITES REY, M. Gramsci mirando al sur. Sobre la hegemonía en los 90. Buenos Aires, M. K\&ai Editor, Colección Teoría Crítica, 1994.

Fecha de recepción: 21 de febrero de 2013

Fecha de aceptación: 6 de junio de 2013 
casos. En caso de ser publicado el artículo, el/los autor/es transfieren todos los derechos de autor a Cátedra Paralela, sin cuyo permiso expreso no podrá reproducirse ninguno de los materiales allí publicados. Asimismo, Cátedra Paralela asume los derechos para editar, publicar, reproducir, distribuir copias, preparar trabajos derivados en papel y/o electrónicos e incluir el artículo en índices nacionales e internacionales o bases de datos. Se solicita a los/as colaboradores/as la entrega de la nota expresa de originalidad y cesión de los derechos de autor/a. La Revista Cátedra Paralela no se hace responsable por los trabajos no publicados ni se obliga a mantener correspondencia con los/as autores/as.

\section{Modelo Nota de Autorización - Revista Cátedra Paralela}

Por la presente autorizo a la Revista Cátedra Paralela, a la publicación del artículo de mi autoría

.........en el $\mathrm{N}^{\circ}$....... del año ......, publicación de la Escuela de Trabajo Social de la UNR y el Colegio de profesionales de Trabajo Social de la $2^{a}$ Circunscripción de la Provincia de Santa Fe.

Se deja constancia de que no corresponde retribución pecuniaria derivada del derecho de autor.

LUGAR Y FECHA:

FIRMA Y ACLARACIÓN: 